consuetudine mansuescit mas, adeo ut resupinatus complectatur canem pedibus et colludat, ita ut nec dente lædat nec ungue."

Caius has a chapter De Cornibus Cervi Palmati, of which he had seen and figured a specimen in the monastery at Kenilworth in Warwickshire :- another chapter, also, on the Bonasus, whose skull and ribs were then preserved in the chapel of Guy of Warwick. In this he also mentions the Wild Cattle of our forests.

\title{
Notices of the Crocodile by the English Crusaders.
}

"De Cocodrillis, \&c.-Cocodrillos apud Damietam invenimus et interfecimus : est autem bestia crudelis, homines et jumenta devorans, apertis oculis solo visu ova sua fovet: exclusi pulli statim fugiunt parentem quasi hostem, quos enim rapere potest in momento glutit et devorat."

“ Agyptii vero honoraverunt Prophetam, sepelientes eum juxta tumulum Regum, memores beneficiorum quæ præstiterat Ægypto, oratione enim sua fugaverat bestias aquarum, quas Græci Cocodrillos appellant." - Historia Captionis Damiete: apud Gale, Historia Anglicance Scriptores XV. vol. ii. p. 452.

They are called Cocodryll in Trevisa's Chronicle.

Richard TAYLOR.

A Monograph of Macrochisma, a genus of Gasteropodous Mollusca belonging to the family Fissurellidæ. By Arthur Adams, R.N., F.L.S.

\section{Macrochisma, Swainson.}

Animal? Shell elongated, clypeiform, radiately ribbed, extremities elevated; foramen very large, elongated, placed near the hind part, with a groove posteriorly; the hind margin sinuated.

1. Macrochisma maxima, A. Adams. M. testâ oblongâ, costis parum elevatis subrugosis, striisque concentricis obsoletis ornatâ, fusco radiatim maculatâ, dorso elevatâ, lateribus planulatis, extremitate anticâ rotundatâ; posticâ elevatâ, subtruncatâ; foramen dilatatum, posticè excavatum. Hab. - ?

2. Macrochisma dilatata, A. Adams. M. testâ ovato-oblongâ, radiatim costatâ, rubrâ, albo variegatâ, utrinque rotundatâ, lateribus dilatatis; foramen oblongum, in medio angustatum.

Hab. — ?

3. Macrochisma hiatula, Swainson, Manual of Malacology, p. 356 .

Fissurella macrochisma, Sow.

M. testâ ovato-oblongâ, radiatim costellatâ, fuscâ, subdepressâ, lateribus concavis, utrinque rotundata; foramen magnum, oblongum, posticè dilatatum, extremitate postica valdè elevata; margine vix sinuato.

Hab. ——?

4. Macrochisma compressa, A. Adams. M. testa angustè oblonga, albidd, roseo radiatim pictâ, costellis granulosis striisque concentricis decussatâ, utrinque rotundata, dorso convexâ, lateribus compressis, in medio inflexis, extremitate posticâ valdè elevatâ; foramen magnum, lanceolatum, posticè dilatatum.

$\mathrm{Hab}$. 
5. Macrochisma megatrema, A. Adams. M. testá ovato-oblonga, albidâ, roseo radiatim pictâ, costellis rugosis striisque concentricis sculptâ, dorso subelevata, lateribus planulatis; foramen ovato-lanceolatum, permagnum.

Hab. —?

6. Macrochisma cuspidata, A. Adams. M. testá ovato-oblongâ, anticè angustatâ, productâ, acuminatâ, posticè elevatâ, rotundatâ, margine valdè undulatâ, fuscatâ, annulis fuscis concentricis ornatâ, lineis elevatis et concentricis cancellatâ, circa foramen pallidâ, extremitate posticâ valdè elevatâ; foramen magnum, cuspidatum, posticè dilatatum.

Hab. Cagayan, in insulis Philippinis; H.C. (Mus. Cuming.)

7. Macrochisma producta, A. Adams. M. testa angustooblongâ, dorso elevatâ, convexâ, albidâ, fusco pallide variegatâ, lineis elevatis striisque concentricis obsoletè decussata, anticè angustâ, productä, lateribus planulatis, extremitate posticâ rotundatâ, elevatâ; margine valdè sinuatâ; foramen perlongum, triangulare, posticè dilatatum.

Hab. in littoribus Australiæ. (Mus. Cuming.)

8. Macrochisma angustata, A. Adams. M. testâ angustâ, oblongâ, dorso elevatâ, utrinque rotundatâ, albidâ, lineis fuscis maculisque rufo-fuscis pictâ et tessellatâ, costellis obtusis subrugosis, lineisque depressis, concentricis, subdistantibus, sculptä, extremitate posticâ elevatâ, margine sinuato; foramen magnum, elongatum, subtriangulare, posticè dilatatum, excavatum. Hab. — ? - From the Proc. of the Zool. Soc. July 23, 1850.

\section{METEOROLOGICAL OBSERVATIONS FOR AUG. 1851.}

Chiswick.-August 1. Cloudy and warm: slight rain. 2-5. Very fine. 6. Fine: densely clouded. 7. Overcast : fine : clear: lightning at night. 8. Very fine. 9. Overcast : cloudy. 10. Cloudy. 13. Sultry. 14. Fine : lightning at night. 15. Cloudy and fine. 16. Very fine. 17. Showery. 18. Cloudy and fine: clear. 19. Very fine : slight haze : clear. 20,21. Very fine. 22. Very hot. 23. Overcast. 24. Heavy showers, with sunny intervals. 25. Very fine. 26. Slight rain. 27. Fine: constant and very heavy rain at night. 28. Fine : densely clouded. 29. Clear and cold : heavy showers, with hail in afternoon: overcast. 30,31 . Cloudy.

Mean temperature of the month $\ldots \ldots \ldots \ldots \ldots \ldots \ldots \ldots \ldots \ldots . \ldots . \ldots 2^{\circ} \cdot 84$

Mean temperature of Aug. 1850 .......................... $59 \cdot 38$

Mean temperature of Aug. for the last twenty-five years . $62 \cdot 21$

Average amount of rain in Aug. ........................... $2 \cdot 41$ inches.

Boston.-Aug. 1. Cloudy: rain P.M. 2-4. Fine. 5-7. Cloudy. 8. Fine. 9-11. Cloudy. 12. Fine. 13. Cloudy : rain early A.M., and lightning P.M. 14. Fine: rain, thunder and lightning P.м. 15. Fine. 16. Fine: rain p.M. 17. Fine. 18. Cloudy. 19. Fine. 20. Cloudy. 21, 22. Fine. 23. Cloudy: rain A.м. 24. Cloudy : rain r.м. 25. Fine. 26. Cloudy : rain P.м. 27. Cloudy. 28. Fine : rain early А.м. 29. Cloudy : rain A.м. and P.м. 30, 31. Cloudy,

Sandwick Manse, Orkney.-Aug. 1. Bright : showers. 2. Cloudy. 3. Bright : clear. 4. Bright : very clear: fine. 5. Clear: fine: very clear: fine. 6. Clear: fine : very clear : fine : aurora. 7. Clear: fine : haze. 8. Cloudy. 9, 10. Cloudy : bright. 11. Cloudy : drops. 12. Drizzle: damp. 13. Rain : damp. 14. Rain : drops : fine. 15. Drops : damp. 16. Clear: fine. 17. Cloudy: clear: fine. 18. Clear: cloudy. 19. Rain : cloudy. 20. Hazy : fine. 21. Rain. 22. Damp : cloudy. 23. Bright: cloudy : thunder. 24. Clear: cloudy. 25. Bright : clear. 26-28. Showers. 29. Showers : drizzle : showers. 30. Bright : clear : aurora. 31. Drizzle : clear : aurora. 


\section{$2 \mathrm{BHL}$ Biodiversity Heritage Library}

Adams, Arthur. 1851. "A monograph of Macrochisma, a genus of Gasteropodous Mollusca belonging to the family Fissurellidæ." The Annals and magazine of natural history; zoology, botany, and geology 8, 350-351. https://doi.org/10.1080/03745486109496235.

View This Item Online: https://www.biodiversitylibrary.org/item/19557

DOI: https://doi.org/10.1080/03745486109496235

Permalink: https://www.biodiversitylibrary.org/partpdf/7374

\section{Holding Institution}

Natural History Museum Library, London

\section{Sponsored by}

Natural History Museum Library, London

\section{Copyright \& Reuse}

Copyright Status: Public domain. The BHL considers that this work is no longer under copyright protection.

This document was created from content at the Biodiversity Heritage Library, the world's largest open access digital library for biodiversity literature and archives. Visit BHL at https://www.biodiversitylibrary.org. 